\title{
n-3 polyunsaturated fatty acids reduced mortality and morbidity after recent myocardial infarction
}

GISSI-Prevenzione Investigators. Dietary supplementation with n-3 polyunsaturated fatty acids and vitamin E after
myocardial infarction: results of the GISSI-Prevenzione trial. Lancet 1999 Aug 7;354:447-55.

QUESTION: In patients with recent myocardial infarction (MI), are n-3 polyunsaturated fatty acids (PUFAs) and vitamin E, singly or in combination, effective for reducing morbidity and mortality?

\section{Design}

Randomised (allocation concealed*), blinded (outcome assessors),* controlled trial with 42 month follow-up.

\section{Setting}

Centres in Italy.

\section{Patients}

11324 patients ( $51 \% \leqslant 60$ y of age, $85 \%$ men) with recent MI (within previous $3 \mathrm{mo}$ ) who had no contraindications to the study dietary supplements and no conditions with unfavorable short-term prognoses. Follow-up was 99.9\%.

\section{Intervention}

Patients were allocated to $n-3$ PUFAs $(n=2836)$, vitamin $\mathrm{E}(\mathrm{n}=2830), \mathrm{n}-3$ PUFAs and vitamin $\mathrm{E}(\mathrm{n}=2830)$, or no supplement $(\mathrm{n}=2828)$. $\mathrm{n}-3$ PUFA was given in 1 gelatin capsule containing eicosa-pentaenoic acid, $850-882 \mathrm{mg}$, and decosahexaenoic acid as ethylasters in the mean ratio of 1:2, respectively. Vitamin E, $300 \mathrm{mg}$, was given as 1 capsule of synthetic $\alpha$-tocopherol.

\section{Main outcome measures}

The combined outcome of all-cause mortality, non-fatal MI, and non-fatal stroke and the combined outcome of cardiovascular death, non-fatal MI, and non-fatal stroke.

\section{Main results}

Analysis was by intention to treat. Both combined outcomes were reduced by n-3 PUFAs at 42 months $(p=0.023$ for death and non-fatal MI and stroke; and $\mathrm{p}=0.008$ for cardiovascular death, non-fatal MI, and ference between groups (table). Combined n-3 PUFAs and vitamin $\mathrm{E}$ led to a reduction in the combined outcome of death, non-fatal MI, and non-fatal stroke $(\mathrm{p}=0.03) \dagger($ table $)$.

\section{Conclusions}

In patients with recent myocardial infarction (MI), n-3 polyunsaturated fatty acids led to a reduction in the combined outcome of all-cause death, cardiovascular non-fatal stroke) (table). Vitamin E did not lead to a dif-

death, non-fatal MI, and non-fatal stroke. Vitamin E alone did not show an effect.

*See glossary.

$\uparrow \mathrm{p}$ value calculated from data in article.

\section{COMMENTARY}

Although many plausible reasons exist to explain why vitamin $\mathrm{E}$ should reduce the adverse consequences of coronary artery disease, it does not seem to do so. I suspect that the positive results of epidemiological studies of vitamin E simply reflect its use among people with healthier lifestyles and do not show a cause-and-effect relation. This study reinforces the necessity of properly done randomised controlled trials (RCTs) to determine whether interventions truly work.

Are the results of this study at odds with those of other RCTs? No, because vitamin $\mathrm{E}$ supplementation resulted in a mix of good and bad results. In the $\alpha$-Tocopherol, $\beta$-Carotene (ATBC) trial, ${ }^{1}$ a slight decrease in the risk for nonfatal acute MI was counterbalanced by a slight increase in fatal coronary artery disease. In the Cambridge Heart Antioxidant Study (CHAOS), ${ }^{2}$ the combined outcome of cardiovascular death and non-fatal acute MI decreased significantly while cardiovascular and total deaths increased slightly. The Heart Outcomes Prevention (HOPE) trial apparently shows a neutral effect. ${ }^{3}$ Therefore, vitamin E cannot be recommended for prophylaxis.

Marine oils and PUFAs, found in fish and marine mammals, have been shown to reduce triglyceride levels; to reduce the interaction between the platelet and vessel wall; and in 1 trial, to reduce the risk for death. ${ }^{4}$

Unless one has the ability or desire to ingest $100 \mathrm{~g} /$ day of fatty fish (about 5 meals/wk), the use of n-3 PUFAs seems to be beneficial.

\section{David Massel, MD \\ Victoria Hospital London, Ontario, Canada}

1 Rapola JM, Virtamo J, Ripatti S, et al. Lancet 1997;349:1715-

2 Stephens NG, Parsons A, Schofield PM, et al. Lancet 1996;347:781-6.

3 Yusuf S. The HOPE study. Presented at the XXIst Congress of the European Society of Cardiology. Barcelona, Spain, 1999.

4 Burr ML, Fehily AM, Gilbert JF, et al. Lancet 1989;2:757-61.

$n$-3 polyunsaturated fatty acids (PUFAs) or vitamin E, or both, v no supplement after recent myocardial infarction (MI)

\begin{tabular}{|c|c|c|c|c|c|}
\hline Outcomes at 42 months & $\begin{array}{l}\text { Supplement } \\
\text { type }\end{array}$ & Supplement & $\begin{array}{l}\text { No } \\
\text { Supplement }\end{array}$ & RRR $(95 \%$ Cl) & NNT (CI) \\
\hline \multirow[t]{3}{*}{ Death, MI, and stroke } & n-3 PUFAs & $12.6 \%$ & $14.6 \%$ & $14 \%(2$ to 25$)$ & 48 (26 to 332 ) \\
\hline & Vitamin E & $13.1 \%$ & $14.6 \%$ & $10 \%(-2$ to 21$)$ & Not significant \\
\hline & Combined & $12.7 \%$ & $14.6 \%$ & $13 \%$ (1 to 24$)$ & 52 (27 to 610$)$ \\
\hline \multirow[t]{3}{*}{ Cardiovascular death, $\mathrm{Ml}$, and stroke } & n-3 PUFAs & $9.2 \%$ & $11.4 \%$ & $19 \%(5$ to 30$)$ & 47 (27 to 177$)$ \\
\hline & Vitamin E & $10.1 \%$ & $11.4 \%$ & $11 \%(-3$ to 24$)$ & Not significant \\
\hline & Combined & $10.1 \%$ & $11.4 \%$ & $12 \%(-3$ to 24$)$ & Not significant \\
\hline
\end{tabular}

¥Abbreviations defined in glossary; RRR, $\mathrm{NNT}$, and $\mathrm{Cl}$ calculated from data in article. $\mathrm{Ml}$ and stroke refer to non-fatal events.
Sources of funding: Bristol-Myers Squibb; Pfizer;

Pharmacia-Upjohn; Società Proditti Antibiotici.

For correspondence: Dr R Marchioli, GISSI-Prevenzione Coordinating Centre, Consorzio Mario Negri Sud, Via Nazionale, 66030 Santa Maria Imbaro, Italy. FAX +39-0872-578240 